\title{
MAPEAMENTO SISTEMÁTICO DE REFERÊNCIAS DO USO DO BIM NA COMPATIBILIZAÇÃO DE PROJETOS NA CONSTRUÇÃO CIVIL
}

\section{Mapping study of refences of the use of BIM in the compatibilization of projects in civil construction}

\author{
Karen Campos Rodrigues ${ }^{1}$, Hygor de Castro Mesquita ${ }^{2}$, Raphael Canedo Eduardo ${ }^{3}$, \\ Heber Martins de Paula ${ }^{4}$
}

Recebido em 20 de janeiro de 2017; recebido para revisão em 02 de fevereiro de 2017; aceito em 17 de março de 2017; disponível on-line em 24 de março de 2017.

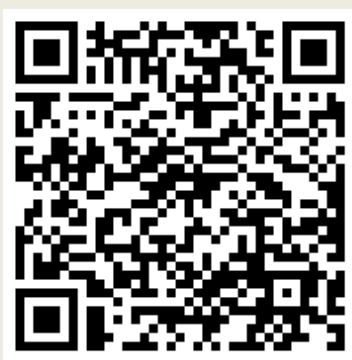

PALAVRAS CHAVE:

Compatibilização;

Gerenciamento de projeto;

BIM;

Mapeamento sistemático.

\section{KEYWORDS:}

Compatibility;

Project management;

BIM;

Mapping study.

\begin{abstract}
RESUMO: O uso da metodologia BIM (Building Information Modeling) prevê a construção de um banco de dados que agrega as informações geradas nos projetos de concepção, necessárias à execução de uma obra de engenharia. A utilização do mesmo se torna justificável por criar um modelo digital que permite o trabalho simultâneo de equipes multidisciplinares sobre uma mesma referência tridimensional. Esta centralização de dados de projeto permite uma melhor gestão das informações mitigando problemas de compatibilidade, bem como fornece uma visão mais holística do processo. Este trabalho tem como objetivo apresentar uma revisão sistemática de publicações e conteúdos abordados a respeito do BIM, verificando as perspectivas da tecnologia, a utilização no ato de projetar e gerenciamento de projetos. A metodologia foi baseada no desenvolvimento de um Mapping Study, tomando como fontes para a pesquisa as seguintes bases de dados indexadas: Portal de Periódicos da Coordenação de Aperfeiçoamento de Pessoal de Nível Superior (CAPES), Scopus, Compendex e Science Direct. Foi realizada ainda uma pesquisa nos periódicos nacionais Ambiente Construído e Gestão de Tecnologia e Projetos e nas bases Scielo e Centro de Referência e Informação em Habitação (Infohab). Os resultados obtidos fornecem um horizonte do progresso da aplicação da tecnologia. Mostra também uma tendência pela busca da desfragmentação das equipes no desenvolvimento dos projetos de engenharia com a utilização do BIM. Assim este trabalho contribui para um melhor entendimento acerca do desenvolvimento de pesquisas relacionadas ao BIM, em suas diversas vertentes, fornecendo referências importantes acerca do tema estudado.
\end{abstract}

* Contato com os autores:

${ }^{1}$ e-mail: karencamposrodrigues@hotmail.com (K. C. Rodrigues )

Graduanda em Engenharia Civil, Universidade Federal de Goiás.

2e-mail: hygorcastro@hotmail.com (H.C. Mesquita)

Graduando em Engenharia Civil, Universidade Federal de Goiás.

${ }^{3}$ e-mail: raphaeleduardo42@gmail.com (R. C. Eduardo )

Graduando em Engenharia Civil, Universidade Federal de Goiás.

${ }^{4}$ e-mail: heberdepaula@ufg.br ( H. M. de Paula)

Doutor, Professor Adjunto, Universidade Federal de Goiás. 


\section{INTRODUÇÃO}

O Building Information Modeling ou Modelagem de informação da construção (BIM) é um modelo digital feito a partir de um arquivo padrão compartilhado entre equipes, cujos elementos possuem dados inteligentes que auxiliam no desenvolvimento de um projeto e no ciclo de vida de uma construção, objetivando melhoria nos processos e resultados.

Em 1990, a empresa Parametric Techonologies Corporation (PTC) expandiu conceitos antes utilizados na modelagem CAD 3D (Computer Aided Design ou Desenho Assistido por Computador), são elas: a Boundary Representation (B-rep) ou Representação por Fronteira e a Constructive Solide Geometry (CSG) ou Geometria Sólida Construtiva. A partir disso, a PTC desenvolveu a ideia de modelagem paramétrica com inserção de parâmetros que o próprio usuário ou o programa podem definir, o software é composto de famílias que possuem informações dos elementos, portanto, carregam várias informações (EASTMAN et al., 2014).

Com a tecnologia do BIM é possível identificar vários gargalos já na fase de projeto, trabalhando com a compatibilização de projetos, o que gera maior produtividade na hora de construir, evitando os retrabalhos e custos desnecessários. Além disso, os softwares BIM possuem inúmeras ferramentas que auxiliam no desenvolvimento do projeto, agregando muitos detalhes e informações nos modelos desenvolvidos.

Os projetos são compostos por várias pranchas com inúmeros detalhes, e geralmente cada sistema (estrutural, hidráulico, elétrico, entre outros) são feitos por profissionais ou empresas diferentes, o que, geralmente, faz surgir conflitos entre os sistemas, e isso só é descoberto na fase de execução, sendo algo comum e que afeta muito o desempenho de uma construção. Portanto, são características cotidianas no mercado da construção: a inexistência de interoperabilidade (trabalho de várias equipes com o mesmo projeto base), incompatibilidade de projetos, mau planejamento, orçamentos frágeis e ineficiência no gerenciamento de obras. Projetos baseados em
BIM são feitos de forma colaborativa entre as equipes e que com essa comunicação a qualidade do projeto e a produtividade das equipes aumentam (OH, LEE, et al., 2015).

$$
\text { De acordo com Smith (2014) a }
$$

metodologia BIM, quando aplicada no gerenciamento de projetos, permite uma integração entre os projetos e os profissionais envolvidos, portanto, os dados são compartilhados fazendo com que os processos de alterações no projeto se tornem automatizados. Dessa forma, os erros comuns da fase de projetos são minimizados ou completamente eliminados.

A modelagem de informação da construção é um elemento que auxilia a viabilização, construção, operação e manutenção, ou seja, todo o ciclo de vida de um projeto. É um conceito que traz avanço para a indústria da Arquitetura, Engenharia e Construção (AEC) com projetos sustentáveis e compatíveis. Porém, segundo Gu e London (2010) existe uma relutância da indústria em mudar as práticas de trabalho, aprender novos conceitos $\mathrm{e}$ inserir novas tecnologias na indústria AEC.

Em vista deste cenário, essa nova forma de modelar e desenvolver projetos faz parte do desenvolvimento da AEC e, consequentemente, do desenvolvimento de um país. Dessa forma, através de pesquisas nacionais e internacionais se faz necessário o conhecimento e aprofundamento neste assunto.

\section{OBJETIVO}

Esse artigo tem como objetivo apresentar uma revisão sistêmica sobre o uso da modelagem BIM no desenvolvimento de projetos de engenharia, apontando o atual estado da arte, as principais linhas em estudo, a evolução e quais as possíveis lacunas por meio de um estudo de mapeamento sistemático.

\section{METODOLOGIA}

Foi realizado um estudo de mapeamento sistemático (Mapping Study) para encontrar 
referências e obter um panorama de publicações e conteúdos abordados a respeito do BIM, conforme metodologia adotada por Paula e Ilha (2016) e Costa et al. (2014).

A busca foi realizada nas seguintes bases de dados internacionais: Portal de Periódicos Capes, Scopus, Compendex e Science Direct. Para realizar a busca foram adotadas combinações de palavras relacionadas ao tema pesquisado, caracterizando as strings de busca. As strings adotadas foram: "BIM AND Perspective", "BIM AND Project", "BIM AND Project management". As combinações de palavras visaram obter referências que abordassem o desenvolvimento e histórico do BIM, a sua utilização em projetos e a gestão de projetos utilizando esta ferramenta. As buscas foram realizadas em junho de 2016, posteriormente as buscas foram realizadas novamente em janeiro de 2017, visando incluir os artigos publicados no segundo semestre de 2016.

As buscas nas bases foram restringidas à artigos de periódicos revisados por pares em inglês. Os resultados das buscas foram transferidos para uma planilha no Microsoft Excel $^{\circledR}$ e classificados quanto à aderência do título e resumo ao tema de estudo. Foram excluídos os artigos que não possuíam acesso gratuito pelo IP do sistema da biblioteca da Universidade Federal de Goiás. Os artigos selecionados foram classificados para utilização na revisão bibliográfica. Como última etapa foi realizada uma revisão das referências utilizadas nos artigos denominada snowball sampling, em busca de artigos de referência na área e que por ventura não tenham sido identificados ou selecionados no mapeamento sistemático. O snowball sampling foi realizado de maneira qualitativa, por meio da análise das referências utilizadas nos artigos classificados como aderentes.

Paralelamente, realizou-se a busca em bases de publicações nacionais nos periódicos Ambiente Construído e Gestão de Tecnologia e Projetos e nas bases Scielo e Centro de Referência e Informação em Habitação (Infohab). Como nas buscas de alguns dos periódicos nacionais, acima citados, não permitiam a combinação de palavras foi usada apenas a palavra-chave "BIM" em todas as bases. Na busca nacional, a seleção quanto à título e resumo aderente foi realizada de maneira conjunta, na página de pesquisa, dado que estas bases não permitem a exportação da busca.

Os dados encontrados foram organizados e os resultados resumidos na forma de tabelas para as buscas nacionais e internacionais, apresentando os artigos que foram classificados como aderentes para cada string. Os dados relativos ao país, ano de publicação, periódico e vertente dos artigos selecionados foram organizados na forma de gráficos e tabelas.

\section{RESULTADOS}

\subsection{MAPEAMENTO SISTEMÁTICO DE REFERÊNCIAS}

O resumo dos resultados obtidos nas buscas das bases de dados internacionais $e$ nacionais são apresentados nas Tabelas 1 e 2, respectivamente. Como a busca na base de dados Scielo não retornou resultados aderentes, ela não é discriminada na Tabela 1.

Dessa forma, por meio do mapeamento sistemático foi criado um banco de dados com 112 referências de bases de dados internacionais e 8 (oito) referências das bases de dados nacionais, totalizando 120 referências aderentes ao trabalho. As bases Scopus e Compendex apresentaram grande número de artigos repetidos entre si, e alguns dos artigos dessas bases que foram classificados em aderentes quanto ao título e resumo possuíam acesso restrito ao texto completo, inviabilizando a sua utilização. A string "BIM AND Perspective" foi a que apresentou maior porcentagem de artigos com título e resumo aderentes e acesso ao texto completo selecionados após o resultado inicial, equivalendo ao valor de 4,22\%, seguida pelas strings "BIM AND Project management" com 2,9\% e "BIM AND Project" com $1,26 \%$

A evolução da publicação anual dos artigos selecionados na busca internacional pode ser vista na Figura 1, onde é possível notar que todos os artigos foram publicados há no máximo uma década, sendo que houve um aumento das 
publicações a partir do ano de 2014. No contexto nacional o ano de 2009 pode ser considerado como um marco para as publicações sobre esse tema, como pode ser visto na Figura 2 com aumento na quantidade a partir do ano de 2015.
Dessa forma, observa-se que o assunto é recente e com grandes possibilidades de campos a serem explorados. Nestes dados não são contabilizados os trabalhos encontrados na análise de snowball sampling.

TABELA 1: Resumo dos resultados obtidos na pesquisa das bases de dados internacionais.

\begin{tabular}{|c|c|c|c|c|c|c|}
\hline \multirow[t]{4}{*}{ Base de dados } & \multicolumn{6}{|c|}{ Expressões-chave } \\
\hline & \multicolumn{2}{|c|}{$\begin{array}{c}\text { BIM AND } \\
\text { Perspective }\end{array}$} & \multicolumn{2}{|c|}{ BIM AND Project } & \multicolumn{2}{|c|}{$\begin{array}{l}\text { BIM AND Project } \\
\text { Management }\end{array}$} \\
\hline & \multicolumn{6}{|c|}{ Número de artigos } \\
\hline & Inicial & $\begin{array}{c}\text { Com título } \\
\text { aderente }\end{array}$ & Inicial & $\begin{array}{l}\text { Com título } \\
\text { aderente }\end{array}$ & Inicial & $\begin{array}{c}\text { Com título } \\
\text { aderente } \\
\end{array}$ \\
\hline Periódicos Capes & 205 & 72 & 913 & 65 & 451 & 142 \\
\hline Scopus & 81 & 28 & 726 & 55 & 355 & 60 \\
\hline Compendex & 49 & 17 & 486 & 44 & 312 & 49 \\
\hline Science Direct & 375 & 23 & 334 & 19 & 502 & 40 \\
\hline Total & 710 & 140 & 2459 & 183 & 1620 & 291 \\
\hline Artigos com título aderente e sem repetições & \multicolumn{2}{|r|}{81} & \multicolumn{2}{|r|}{93} & \multicolumn{2}{|r|}{134} \\
\hline Artigos selecionados após leitura do resumo & \multicolumn{2}{|r|}{33} & \multicolumn{2}{|r|}{39} & \multicolumn{2}{|r|}{50} \\
\hline Artigos com acesso ao texto completo & \multicolumn{2}{|r|}{30} & \multicolumn{2}{|r|}{31} & \multicolumn{2}{|r|}{47} \\
\hline Total após snowball sampling & \multicolumn{6}{|c|}{112} \\
\hline
\end{tabular}

TABELA 2: Resumo dos resultados obtidos na pesquisa das bases de dados nacionais.

\begin{tabular}{|c|c|c|}
\hline \multirow{2}{*}{ Periódicos } & \multicolumn{2}{|c|}{ Número de artigos } \\
\hline & Inicial & Aderente \\
\hline Ambiente Construído & 12 & 2 \\
\hline Gestão de Tecnologia e Projetos & 20 & 2 \\
\hline InfoHab & 175 & 4 \\
\hline Total & 207 & 8 \\
\hline Artigos com título aderente e sem repetições & & 8 \\
\hline Artigos selecionados após leitura do resumo & & 8 \\
\hline Artigos com acesso ao texto completo & & 8 \\
\hline Total após snowball sampling & & 8 \\
\hline
\end{tabular}




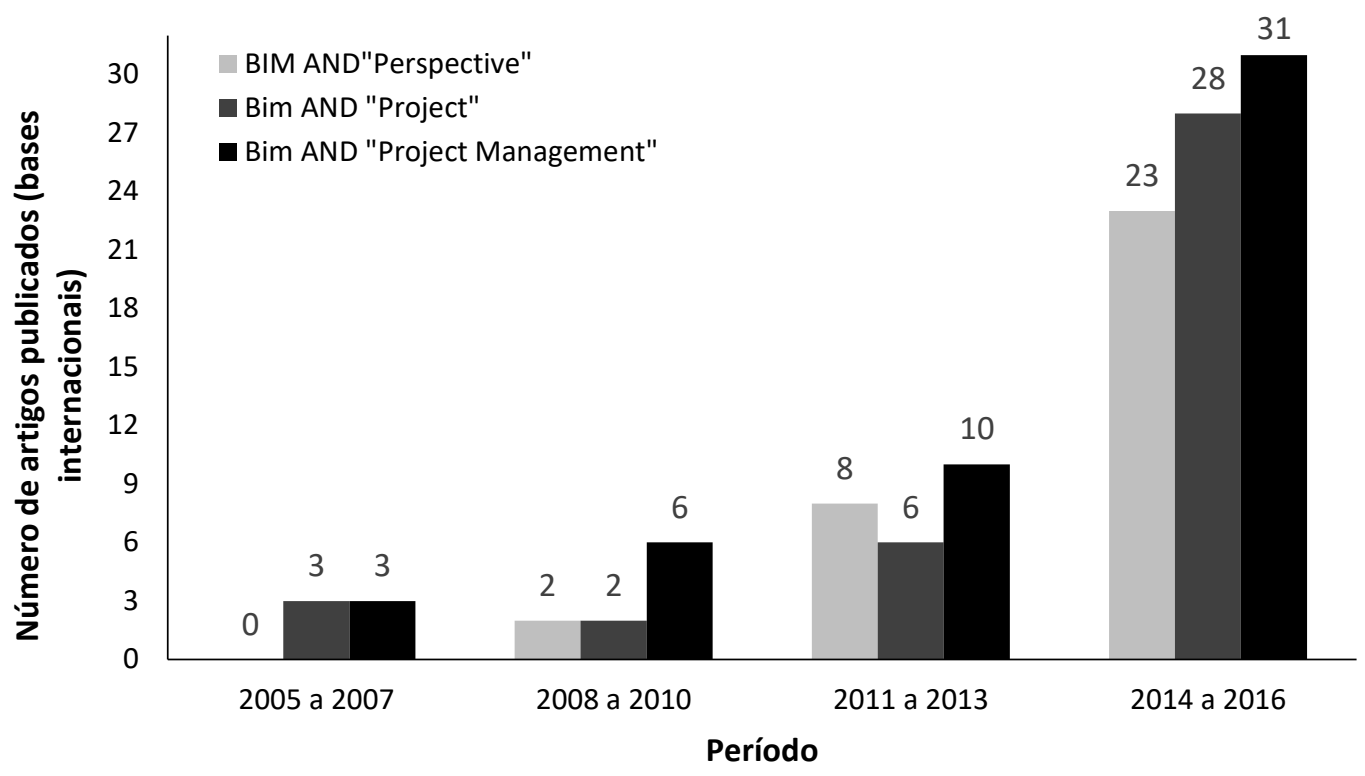

FIGURA 1 - Evolução anual das publicações internacionais de artigos por string de busca.

FONTE: Autoria Própria.

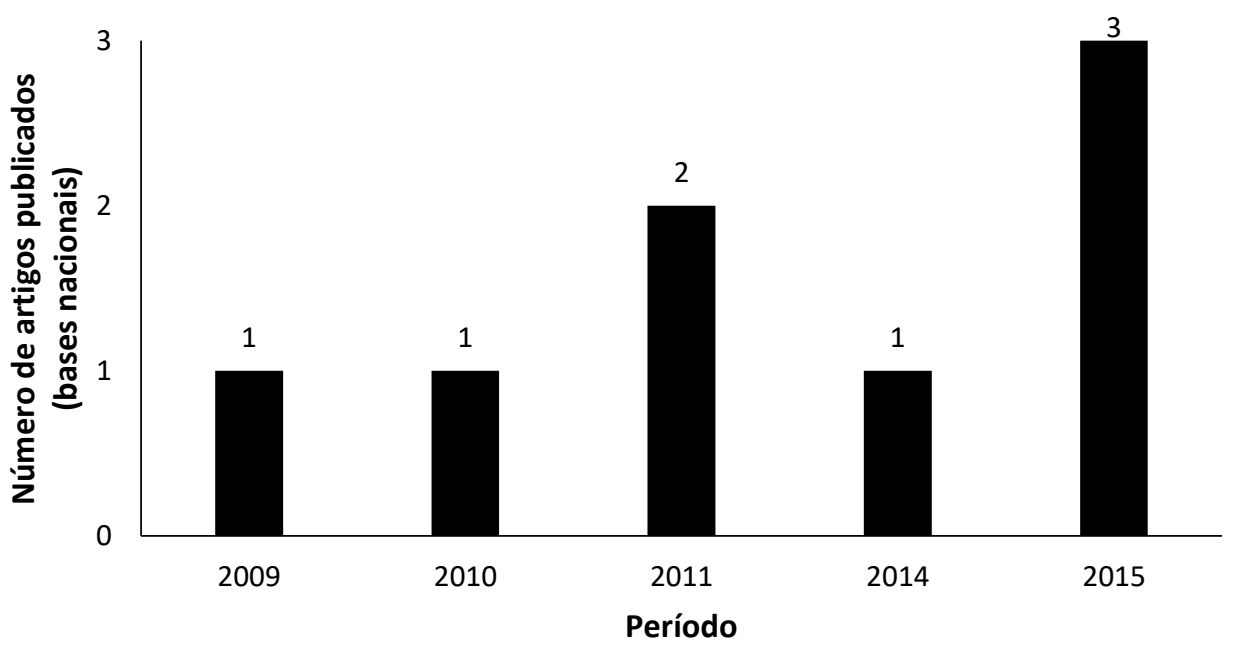

FIGURA 2 - Evolução anual da publicação de artigos em bases nacionais. FONTE: Autoria Própria.

Os periódicos que possuem a maior quantidade de artigos selecionados no mapeamento estão dispostos na Tabela 3. 0 periódico Automation in Construction foi o que apresentou maior número de publicações, com 39 artigos publicados entre os anos de 2007 a 2016. Na Figura 3 são mostrados os países com maior número de artigos selecionados, nota-se que a Austrália, China, Estados Unidos e Reino Unido são os países que possuem maior número de artigos publicados entre os que foram selecionados.

Os artigos selecionados na busca internacional foram classificados quanto à vertente adotada, os resultados são apresentados nas Figuras 4 e 5 . As vertentes foram separadas em tópicos relacionados à gestão de projetos, os quais abordam a questão conceitual do BIM; e relacionados ao desenvolvimento de projetos, que abordam a possibilidade de utilização do BIM em projetos de engenharia. Dentro do tópico de gestão de projetos, a vertente mais abordada é o trabalho em equipes colaborativas, com 26 artigos selecionados. Quanto ao tópico de desenvolvimento de projeto, a vertente mais abordada é a modelagem BIM 4D, com 14 artigos selecionados. 
TABELA 3: Principais periódicos internacionais com publicações nos artigos selecionados.

Advanced Engineering Informatics Número de artigos publicados

Architectural Engineering and Design Management 2

Automation in Construction $\quad 39$

Built Environment Project and Asset Management 2

Construction Innovation 3

Consulting-Specifying Engineer 2

Electronic Journal of Information Technology in Construction 2

International Journal of Advanced Robotic Systems 5

International Journal of Project Management 2

Journal of Civil Engineering and Management 2

Journal of Construction Engineering and Management 2

Journal of Information Technology in Construction 3

Journal of Management in Engineering 2

Practice Periodical on Structural Design and Construction 2

Procedia - Social and Behavioral Sciences 3

$\begin{array}{ll}\text { Procedia Engineering } & 10\end{array}$

Structural Engineer $\quad 2$

Visualization in Engineering 2

FONTE: Autoria Própria.

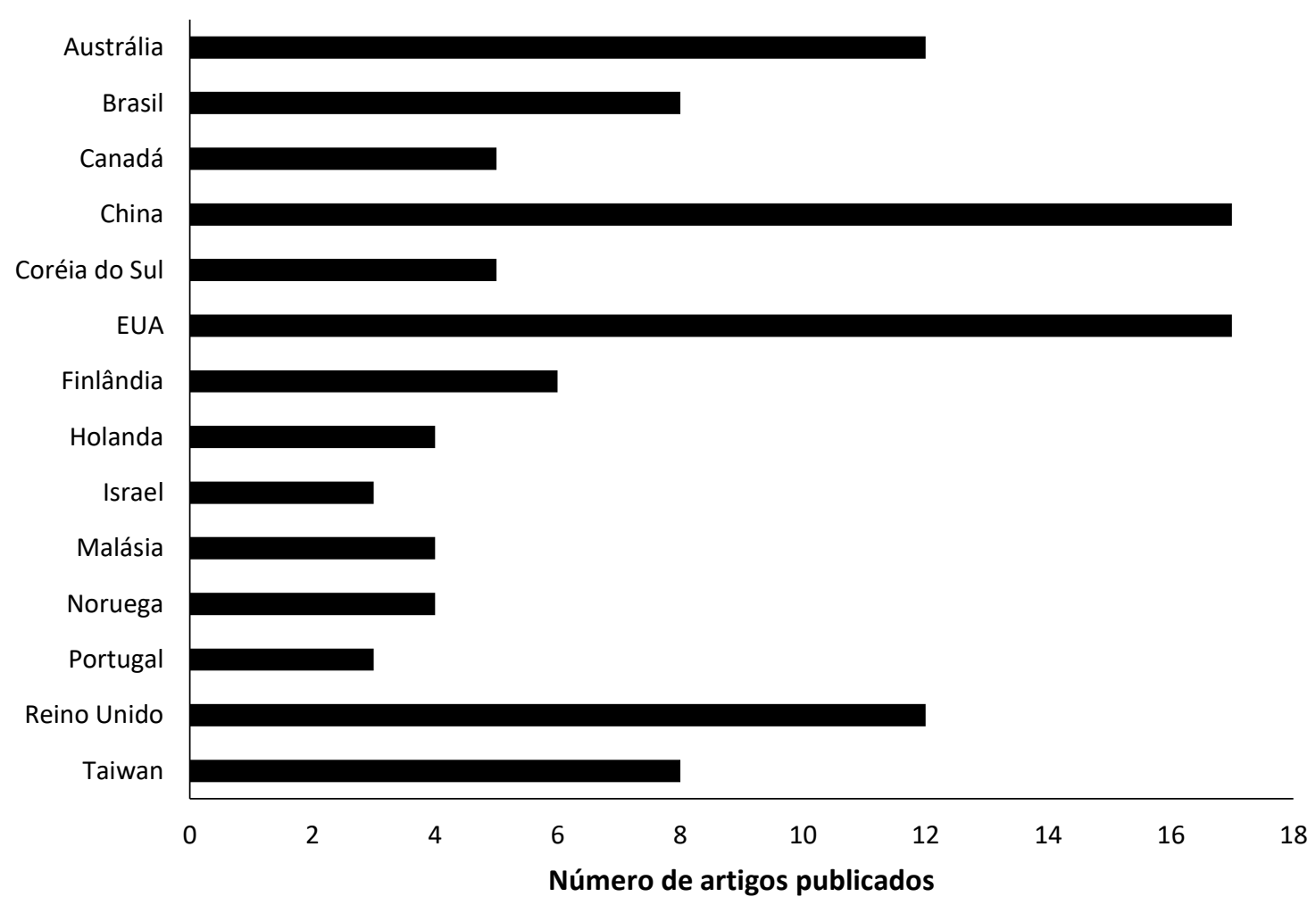

FIGURA 3 - Principais países com publicações entre os artigos selecionados.

FONTE: Autoria Própria.

As principais vertentes identificadas na padrão também observado na busca de bases busca nacional são mostradas na Figura 6. internacionais.

A maior quantidade de artigos aborda o BIM 4D, 


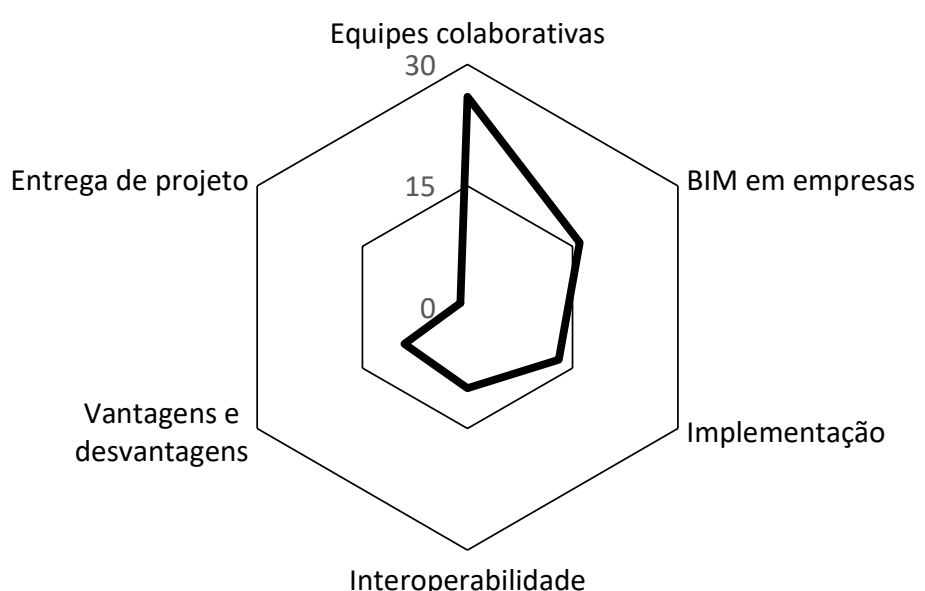

FIGURA 4 - Principais vertentes sobre "Gestão de projetos" na busca internacional. FONTE: Autoria Própria.

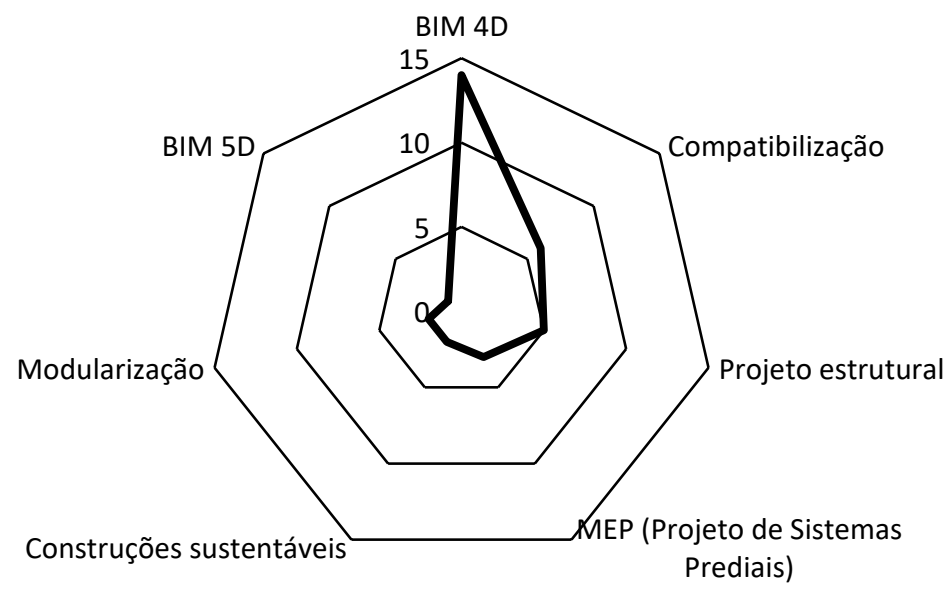

FIGURA 5 - Principais vertentes sobre "Desenvolvimento de projetos" na busca internacional. FONTE: Autoria Própria.

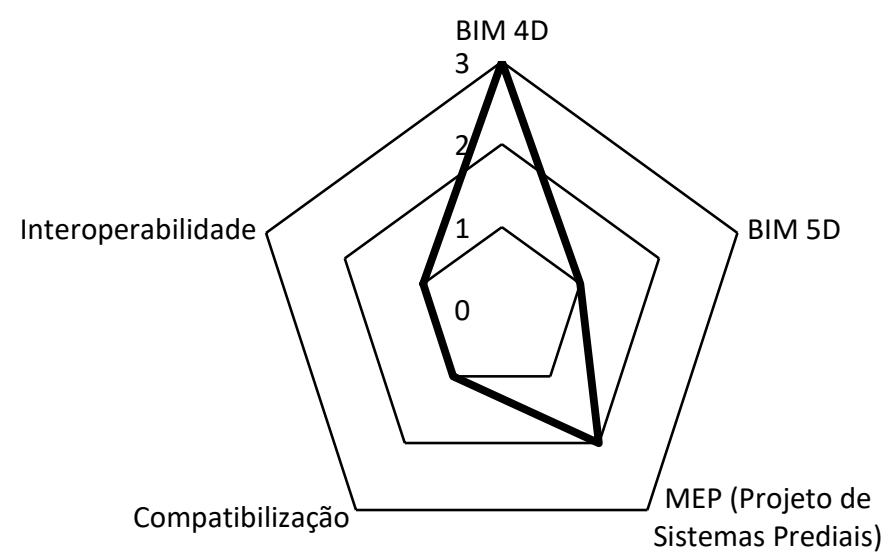

FIGURA 6 - Principais vertentes identificadas na busca nacional. FONTE: Autoria Própria. 
Os gráficos acerca das vertentes possibilitam a separação das áreas que mais têm atraído a atenção de pesquisadores. Nota-se que de todos os trabalhos encontrados no mapeamento sistemático, seja em bases de dados nacionais ou internacionais, apenas sete tratam da compatibilização de projetos, indicando uma lacuna de estudo nessa subárea.

\subsection{EVOLUÇÃO E DEFINIÇÕES DO BIM}

Para entender mais o que é o BIM e sua capacidade é fundamental que se entenda a história dos primeiros projetos, desde os desenhos feitos à mão, até a inserção de computação gráfica e a evolução da mesma.

A princípio na engenharia todos projetos eram feitos à mão com auxílio de instrumentos tradicionais de desenho. O surgimento dos computadores e depois das impressoras foram os pontos de partida para o desenvolvimento de softwares CAD (Computer Aided Design ou desenho assistido por computador) que permitiram reproduzir representações gráficas com precisão, contendo diversas ferramentas, impressão e armazenamento.

Inicialmente as modelagens eram direcionadas principalmente para indústria de filmes, projetos e até jogos. As primeiras modelagens em três dimensões (3D), contendo formas volumétricas com um volume definido surgiram na década de 1960. Porém, só em 1973 que surgiram ferramentas de criação e edição de formas para projetos em 3D. Essas possuíam duas formas de modelagem: a representação por fronteira (Boundary Representation, B-rep) e a geometria sólida construtiva (Constructive Solid Geometry, CSG) que posteriormente se fundiriam (EASTMAN et al., 2014).

No início de 1980 surgiu a modelagem de edifícios 3D, com os softwares CAD da época, o que era um avanço para a engenharia em geral. Entretanto os computadores não possuíam o processamento necessário para gerenciar o enorme fluxo de informações demandado. Outro problema é que os sistemas de licenças eram caros para a época. Por fim, os projetistas não aceitavam bem a ideia do 3D e preferiam projetar em 2D. Porém, a indústria de manufaturas e aeroespacial tiveram uma visão além, e já imaginavam os potenciais da ferramenta com o incremento de relatórios bem definidos, capacidade integrada de análise, redução de erros, dentre outros (EASTMAN et al., 2014).

Ainda nos anos 1990, principalmente a Parametric Technologies Corporation (PTC) estendeu os conceitos da CSG e B-rep e desenvolveram a ideia de modelagem paramétrica com a inserção de parâmetros que o próprio usuário ou o programa podem definir. Ao invés de inserir um desenho de elemento é definida uma família de modelos, os elementos da família se relacionam e permitem que alterações possam ocorrer sem retrabalho de desenho, ou seja, as modificações ocorrem automaticamente, e as formas podem ser em duas ou três dimensões (EASTMAN et al., 2014).

Tendo como base a importância econômica que a construção representa para o mundo, é imprescindível a necessidade de aprimorar técnicas e implantar tecnologia a favor da melhoria tanto dos processos de construção, quanto do ciclo de vida da edificação. Visando essa oportunidade de crescimento das atividades ligadas à construção surge a tecnologia BIM (Build Information Modelling ou Modelagem da Informação da Construção) como grande aliada para este fim.

As evoluções na indústria de Arquitetura, Engenharia e Construção (AEC) exigiram a demanda por avanços na tecnologia, pois nas últimas décadas a mesma vem sofrendo com fatores que interferem diretamente no desempenho das obras, são esses:

- Inexistência de interoperabilidade;

- Incompatibilidade de projetos;

- Mal planejamento;

- Levantamento de materiais deficitário;

- Orçamentação frágil;

- Ineficiência no gerenciamento;

- Atraso nas entregas de obras.

Diante desses fatores é notória a necessidade de uma modernização na engenharia 
que permita para os construtores, projetistas, e empreendedores a existência de uma obra melhor projetada. Essa modernização possibilitará a integração de equipes usufruindo da interoperabilidade de softwares, compatibilização de projeto, além da extração transparente de dados reais da obra (como lista de materiais e orçamento), permitindo ainda que o projeto seja atualizado automaticamente quando houverem alterações no mesmo (EASTMAN et al. 2014).

O BIM vem crescendo e sendo aceito no mercado, pois permite que vários dos problemas que se teriam em obra sejam resolvidos logo na fase de projeto, proporcionando uma melhor integração entre as equipes envolvidas. Essa característica permite uma reprodução mais próxima do real na questão de composições de materiais e, caso haja alterações no empreendimento, torna-se fácil e rápida a correção do projeto.

As siglas "BIM" não possuem uma definição padrão normatizada. A maioria dos autores traduzem como Modelagem da Informação da Construção, outros já trocam modelagem por modelo. Para entender melhor o conceito várias definições de diversos autores foram analisadas.

Define-se BIM como "o processo de criação e uso de modelos digitais para projeto, construção e/ou operações de projetos" (HILL, 2009). Neste conceito o BIM é interpretado apenas como uma ferramenta de reprodução gráfica para um projeto, portanto, tem o mesmo efeito de ferramentas $C A D$, não sendo exploradas as várias vantagens que ele possui. Esta definição traz a visão dos empreiteiros, relacionando o BIM como uma ferramenta de documentação.

Outra definição é o BIM como uma ferramenta inteligente em que é possível a inserção de informações no projeto para auxiliar a extração de soluções que melhorem a construção:

Um modelo inteligente de construção virtual 3D que pode ser construído digitalmente contendo todas informações dos aspectos da construção - em um formato inteligente que pode ser usado para desenvolver soluções otimizadas para construção que diminuem riscos e aumento de custo. (WOO, WILSMANN e KANG, 2010).

Zuppa et al. (2009) define que o "BIM foi mais frequentemente percebido como uma ferramenta para visualização e coordenação do trabalho de Arquitetura, Engenharia e Construção (AEC) e evitando os erros e omissões". A ideia da interoperabilidade do BIM, podendo haver a interação de diversas equipes no mesmo projeto padrão, o que faz com que erros de compatibilização sejam diminuídos ou eliminados.

O BIM como uma ferramenta de simulação que auxilia a visualização das etapas da obra. "O desenvolvimento e o uso de um modelo de dados de software de computador multifacetado, não só para documentar um projeto de construção, mas para simular a construção e operação de uma nova instalação ou uma reforma" (GENERAL SERVICES ADMINISTRATION, 2007)

A ideia de usar elementos de famílias para conseguir um projeto fiel ao que será executado, definindo o BIM como "o processo de projeto, construção e uso da edificação ou instalação de infraestrutura utilizando informações sobre objetos virtuais" (PAS 1192-2, 2013)

As definições de buildingSMART (2010) e Chien, Wu e Huang (2014) afirmam que o BIM auxilia e traz informações confiáveis que vão ajudar a tomar decisões em todo o ciclo de vida da obra, podendo ser desde a construção até a demolição.

BIM é uma representação digital das características físicas e funcionais de uma instalação. Este, serve como um recurso compartilhado de conhecimento para obter informações sobre a instalação formando uma base confiável para as decisões durante o seu ciclo de vida, desde a concepção em diante. O BIM é uma representação digital partilhada fundada em normas abertas de interoperabilidade (BUILDING SMART, 2010).

"BIM é uma tecnologia em desenvolvimento no qual os modelos de informações digitais são empregados em um espaço virtual para alcançar alta qualidade, construção eficiente e gerenciamento por todo o ciclo de vida de uma instalação" (CHIEN, WU e HUANG, 2014). As obras são cada vez mais 
complexas exigindo uma grande equipe com vários profissionais especializados em áreas diferentes. Desta forma, existe a necessidade de um intercâmbio de dados entre as equipes que acaba gerando conflitos entre profissionais envolvidos. Tais conflitos são consequência do grande volume de detalhes exigidos por um projeto (OH et al., 2015).

Com o BIM existe a interoperabilidade que permite que essas várias equipes trabalhem no mesmo arquivo base, evitando que um profissional mude, ou seja, omisso ao projeto de outros. Tal aspecto permite, inevitavelmente, que os envolvidos projetem de forma compatibilizada, eliminando interferências indesejadas no projeto, como uma tubulação passando em uma viga.

A interoperabilidade permite que as informações de um arquivo sejam transportadas com ele quando inseridas em outros aplicativos. Assim, é eliminado o retrabalho de replicar dados que já foram inseridos anteriormente. Essa era uma lacuna entre os softwares, pois, cada aplicação tinha seu próprio formato. O Industry Foundation Classes (IFC) é um modelo de dados que permite esse intercambio dentre as diversas aplicações do mercado.

O planejamento é fundamental para o acompanhamento da obra, é através deste que se faz o cronograma, definindo quanto tempo, momento de implantação e a sequência das tarefas. No BIM existe a possibilidade de atrelar o cronograma com os elementos gráficos da construção, neste caso é considerado a quarta dimensão da plataforma, ou seja, o BIM 4D.

Com o BIM é prático e rápido listar todos os materiais do projeto, pois é algo que o software faz automaticamente e de forma precisa. Com a extração dos quantitativos e medidas dos materiais é possível fazer a orçamentação. Pode haver a exportação das tabelas para um programa específico de orçamento ou fazer manualmente com o uso de planilhas eletrônicas associadas às tabelas disponíveis de orçamento, como a da Caixa Econômica Federal (SINAPI), TCPO, dentre outras. A parte de orçamento é considerada a quinta dimensão da plataforma, o BIM 5D.

\subsection{BENEFÍCIOS E DESAFIOS DO BIM}

Os benefícios envolvidos no processo de desenvolvimento proposto pelo Building Information Modelling dependem diretamente do grau de aplicação do mesmo nas empresas de Arquitetura, Engenharia e Construção (AEC). Como levantado por Eastman et al. (2014) é pouco provável que todas as reais vantagens geradas pela tecnologia sejam observadas em todos os projetos não desenvolvidos completamente na plataforma.

A otimização dos projetos de construção na resolução de problemas com custos e má utilização de insumos tem mostrado resultados promissores, bem como a utilização de equipes colaborativas têm reduzido os erros de concepção e aumentado a produtividade na indústria da construção (LI et al., 2014; MIETTINEN e PAAVOLA, 2014). Entretanto como não existem estudos que abranjam todas as facetas da aplicação do BIM nos projetos de construção, os executivos de uma empresa da área podem se encontrar em um dilema na decisão de usar ou não a tecnologia (LI et al., 2014), uma vez que tanto os custos associados quanto os benefícios propriamente ditos são de difícil análise e quantificação (LU et al., 2014).

\subsubsection{Fase de pré-construção}

A aplicação do BIM nas etapas iniciais permite que sejam levantados dados referentes à viabilidade da construção de maneira mais cuidadosa. Com informações mais precisas é possível verificar com clareza se as metas definidas, tanto de custo quanto de prazo, poderão ser alcançadas já nas fases conceituais de projeto (EASTMAN et al., 2014).

\subsubsection{Fase de projeto}

No desenvolvimento em BIM, a base de todo o projeto é um modelo com as características físicas e atributos dos materiais empregados. Tal modelo por ser projetado tridimensionalmente permite que todas as vistas geradas possuam exatamente as características que the foram atribuídas. Esse aspecto permite que possam ser visualizadas dimensões consistentes em qualquer 
etapa do projeto (EASTMAN et al., 2014). A Figura 7 mostra como as informações extraídas do modelo 3D mantem suas características em diferentes configurações de vista.

Tendo o modelo tridimensional em mãos a extração de desenhos 2D pode ser feita de maneira rápida, precisa, e sem a necessidade de retrabalho caso ocorram modificações de baixo nível no projeto (EASTMAN et al., 2014). Desta maneira, as mudanças de posicionamento de elementos (como janelas ou portas) nas plantas baixas resultam em uma atualização completa de todas as vistas e tabelas de quantitativos do projeto. Evitando, assim, que informações imprecisas sejam enviadas a campo.

Os elementos projetados possuem atributos de objetos. Uma parede entende que é um elemento linear composto por várias camadas (bloco, revestimento etc.), e não somente duas linhas paralelas traçadas em um plano cartesiano. Desta maneira, é possível que seja feita a extração de quantitativos mesmo durante as etapas iniciais. Sendo possível manter todos os envolvidos conscientes dos custos associados às mudanças feitas no projeto, mesmo antes do detalhamento final. Permitindo, assim, que sejam tomadas as melhores decisões de projeto, aliando a expectativa de custo do proprietário com a funcionalidade proposta à construção (EASTMAN et al., 2014; Ll et al., 2014).

A busca por soluções sustentáveis também atinge as construções do século XXI. Através do modelo tridimensional resultado do BIM podem ser feitas inúmeras análises para incrementar o desempenho energético do projeto, antes impossíveis pela simples análise bidimensional dos ambientes. Pelo posicionamento georeferenciado e definição de aparelhos, é possível que sejam feitas análises de insolação e iluminação, bem como verificar rotas de ventilação para melhor utilização de climatizadores. Soluções como a extensão Light Analysis para Revit ${ }^{\circledR}$ permitem que análises de iluminação tanto solar quanto artificial sejam aplicadas a edificações de qualquer porte. A Figura 8 mostra a penetração da luz em um edifício realizada pelo programa, montando uma escala de cor que varia de amarelo à azul conforme a presença de luz do sol e vermelho caso não haja iluminação.
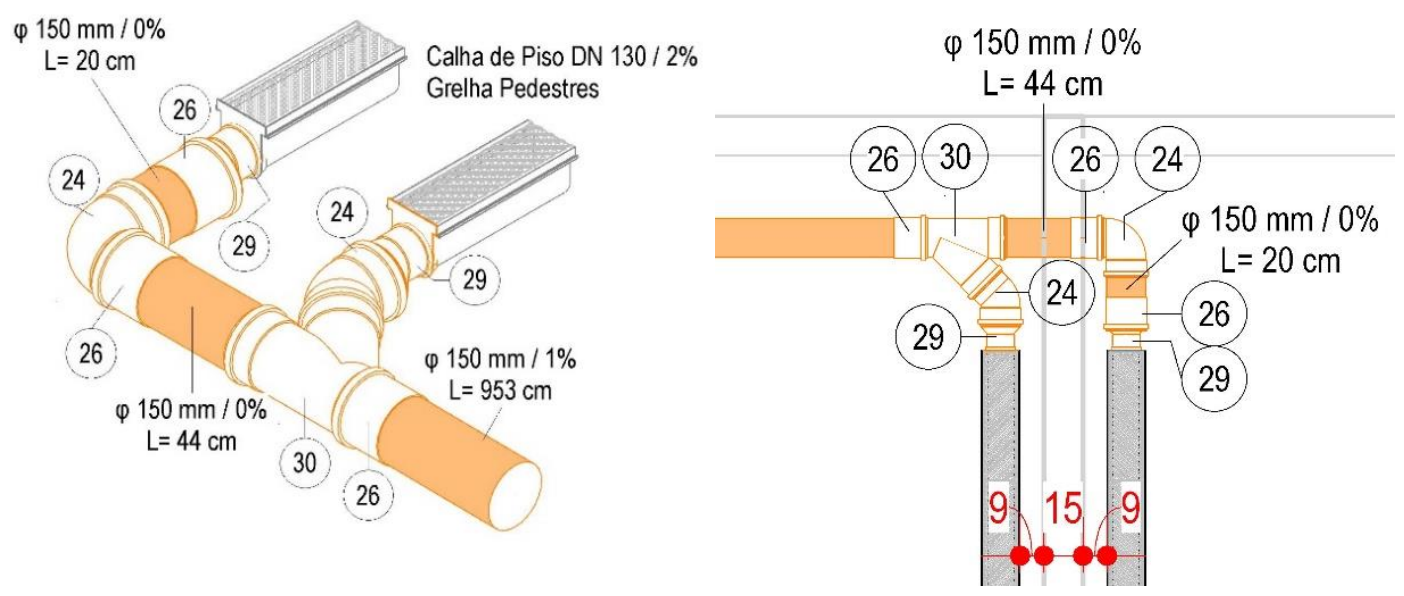

FIGURA 7 - Detalhe isométrico e em planta de um sistema de calhas de piso para águas pluviais. FONTE: Autoria Própria. 


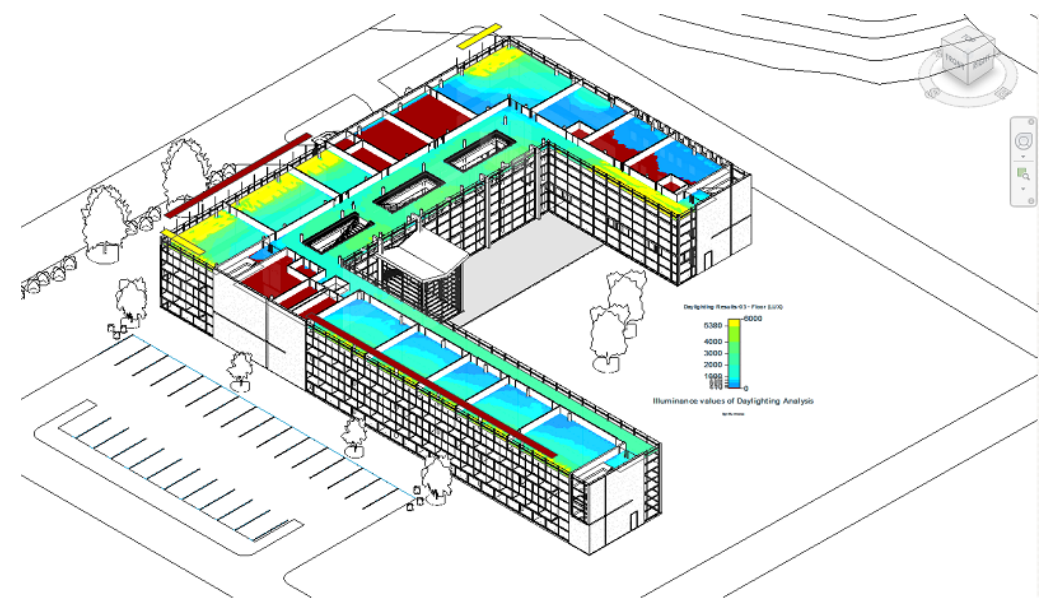

FIGURA 8 - Exemplo de análise de iluminação. FONTE: Autodesk (2015).

\subsubsection{Fase de construção}

$\mathrm{Na}$ construção um benefício valioso é a deteç̧ão de erros e omissões nos projetos (MIETTINEN e PAAVOLA, 2014). A fonte para todas as referências $2 \mathrm{D}$ e $3 \mathrm{D}$ do projeto é um único arquivo tridimensional, logo as inconsistências geradas por desenhos 2D são completamente eliminadas (EASTMAN et al., 2014). Como é possível que seja feita a verificação no lançamento de todas as disciplinas (estrutural, mecânica e hidráulica), podem ser evitados, na fase de planejamento, erros que atrasariam obra caso não fossem descobertos antes de chegarem ao canteiro.

É possível ainda que seja feita uma sincronização das tarefas a serem executadas no canteiro com os elementos presentes no modelo. Esse planejamento, chamado de BIM 4D, permite visualizar no ambiente virtual o progresso da obra e antecipar possíveis problemas gerados no canteiro.

Li et al. (2014) realizou um estudo de caso no Shangai Recovery Center onde, através da aplicação da modelagem tridimensional, foi possível resolver 500 problemas críticos no projeto de instalações hidráulicas e mecânicas. Pelo agendamento das tarefas, o programa de execução da obra, ainda, pode ser reduzido em três meses.

Uma vez que o BIM fornece um modelo preciso, é possível que seja feito um projeto melhor racionalizado. Com um canteiro mais enxuto, e reduzindo a necessidade de grandes estoques, é possível realizar um melhor gerenciamento de pessoal, equipamentos e materiais. Permitindo assim uma melhor colaboração entre as equipes presentes no canteiro e reduzindo custos (EASTMAN et al., 2014).

\subsubsection{Fase de pós-construção}

Uma vez atualizado com as modificações feitas na obra, um as-built em BIM é um banco de dados de tudo que fora utilizado na construção. Com as informações fornecidas por ele em mãos é possível verificar apropriadamente o funcionamento de todos os sistemas prediais após finalização da obra (EASTMAN et al., 2014).

\subsubsection{Desafios}

Equipes colaborativas podem permitir que os projetos sejam feitos de maneira mais integrada e com menor possibilidade de erros. Entretanto, para que esse cenário ocorra é necessário que todos os projetos sejam feitos na plataforma BIM. Caso uma das partes não forneça os arquivos já modelados tridimensionais da sua disciplina, construí-los através das referências bidimensionais gera custos de adaptação e induzem o projeto como um todo aos mesmos erros observados na metodologia tradicional (EASTMAN et al., 2014).

O intercâmbio de informações entre equipes que trabalham com diferentes softwares também deve ser analisado com certo critério. Caso o mesmo não seja feito de maneira 
correta, existe uma tendência que ocorram perdas de informações na conversão dos arquivos. Tais perdas geram retrabalho, e por consequência maiores custos, sendo frequentemente considerados como fatores de inibição na adoção da plataforma (HU et al., 2016).

$$
\text { A mudança no processo de }
$$
desenvolvimento dos projetos envolve mais do que simplesmente uma mudança de software, treinamento e atualização de hardware instalado (EASTMAN et al., 2014). A efetiva implantação do BIM requer a implementação de novas políticas e relacionamento entre as partes envolvidas numa indústria que hoje é altamente fragmentada (MENA et al., 2009; KRAATZ, SANCHEZ e HAMPSON, 2014).

Tal fragmentação na indústria é considerada como um gargalo que deve ser colocado na balança. Visto que normalmente tal fato impede que o conhecimento adquirido em um determinado projeto seja levado adiante para outros no futuro (BRYDE, BROQUETAS e VOLM, 2013).

\subsubsection{Na prática}

Através da análise de 35 estudos de caso, Bryde, Broquetas e Volm (2013) verificaram em quais áreas a utilização do BIM têm trazido benefícios. O estudo feito pelos autores levantou aspectos como custos, comunicação entre os envolvidos no projeto, aumento da qualidade e problemas de software. Os Quadros 1 e 2 indicam as ocorrências Positivas e Negativas levantadas pelos autores, respectivamente.

QUADRO 1: Ocorrências positivas quanto ao uso do BIM

\begin{tabular}{|l|c|c|c|}
\hline \multicolumn{1}{|c|}{ Critério analisado } & Ocorrências & Total de projetos & \% total de projetos \\
\hline Redução ou controle de custos & 29 & 21 & $60.00 \%$ \\
\hline Redução ou controle de prazos & 17 & 12 & $34.29 \%$ \\
\hline Melhorias na comunicação & 15 & 13 & $37.14 \%$ \\
\hline Melhorias de coordenação & 14 & 12 & $34.29 \%$ \\
\hline Aumento ou controle de qualidade & 13 & 12 & $34.29 \%$ \\
\hline Redução de riscos & 8 & 6 & $17.14 \%$ \\
\hline Esclarecimentos no lançamento & 3 & 3 & $8.57 \%$ \\
\hline Melhorias na organização & 2 & 2 & $5.71 \%$ \\
\hline Problemas de Software & 0 & 0 & $0.00 \%$ \\
\hline
\end{tabular}

QUADRO 2: Ocorrências negativas quanto ao uso do BIM.

\begin{tabular}{|l|c|c|c|}
\hline \multicolumn{1}{|c|}{ Critério analisado } & Ocorrências & Total de projetos & \% total de projetos \\
\hline Redução ou controle de custos & 3 & 2 & $5,71 \%$ \\
\hline Redução ou controle de prazos & 4 & 3 & $8,57 \%$ \\
\hline Melhorias na comunicação & 0 & 0 & $0,00 \%$ \\
\hline Melhorias de coordenação & 7 & 3 & $8,57 \%$ \\
\hline Aumento ou controle de qualidade & 0 & 0 & $0,00 \%$ \\
\hline Redução de riscos & 2 & 1 & $2,86 \%$ \\
\hline Esclarecimentos no lançamento & 0 & 0 & $0,00 \%$ \\
\hline Melhorias na organização & 2 & 2 & $5,71 \%$ \\
\hline Problemas de Software & 9 & 7 & $20,00 \%$ \\
\hline
\end{tabular}


Pela análise dos dados obtidos, é possível verificar que através da aplicação do BIM existe o melhoramento em alguns aspectos dos projetos de construção. O custo foi o critério com maior expressividade, entretanto também merecem menções as melhorias na comunicação das equipes multidisciplinares e os melhores esclarecimentos permitidos pelo projeto tridimensional. Em comparação, os desafios impostos pela implementação são consideravelmente menores, sendo gerados em sua grande maioria por problemas de software e hardware (BRYDE, BROQUETAS e VOLM, 2013).

Um ponto a ser notado é que a quantidade de benefícios não possui ligação direta com o tamanho do projeto, assim como ponderado pelos autores. Uma vez que foram comparadas construções dispares como a Shangai Tower e o Springfield Literacy Center - com $380.000 \mathrm{~m}^{2}$ e $4.600 \mathrm{~m}^{2}$ respectivamente - e não foi observada tal relação. Os prédios citados são vistos nas Figuras 9 e 10.

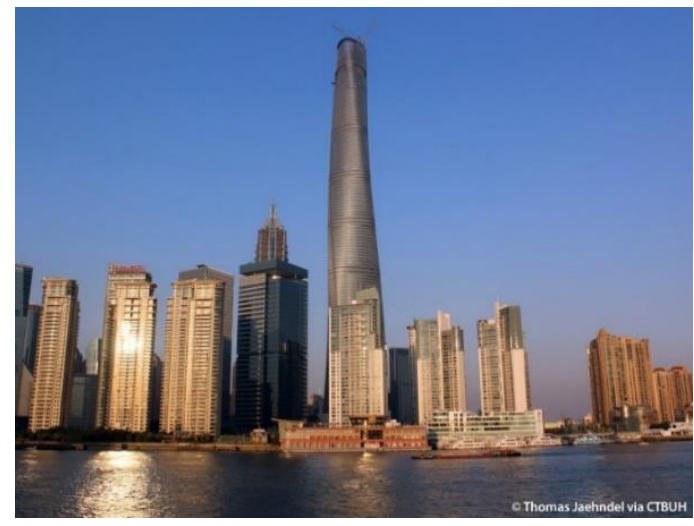

FIGURA 9: Shangai Tower (ao centro). FONTE: Arch20 (2015).

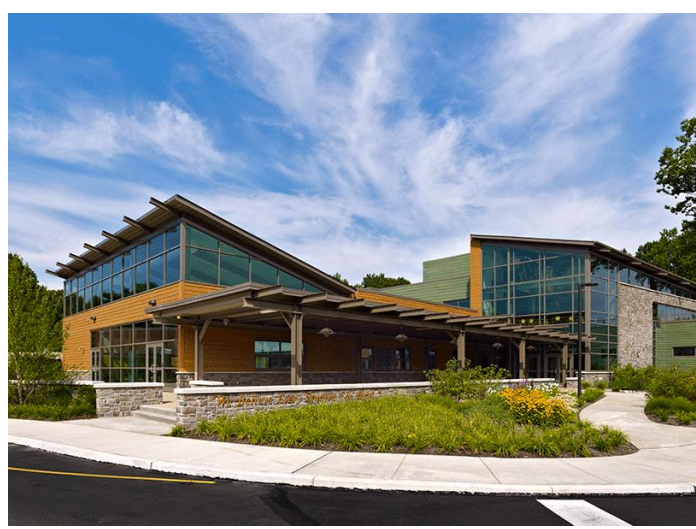

FIGURA 10: Springfield Literacy Center. FONTE: EPG (2017).

\subsection{EQUIPES COLABORATIVAS E O USO DO BIM EM EMPRESAS AEC}

Em um processo tradicional de produção da construção, conhecido como projeto-propostaconstrução ilustrado na Figura 11, inicialmente é feito o projeto da obra, geralmente desenvolvido por diferentes escritórios de arquitetura e engenharia especializados em cada subsistema. Todos os projetos então são reunidos e é elaborado o orçamento com base nos quantitativos e composições de serviços a serem realizados, constituindo assim a etapa de proposta. O proprietário então seleciona a melhor proposta de projeto, que será utilizada para a construção da edificação, a forma de seleção utilizada, geralmente, é a de melhor preço, ou melhor, técnica. A próxima etapa é a produção ou execução da mesma. É possível que seja escolhida também a etapa de execução, dentre várias propostas apresentadas.

O processo descrito pode ser considerado como linear, uma vez que os responsáveis pela elaboração dos projetos não se envolvem na etapa de produção e vice-versa, fato que ocasiona erros de compatibilização, modificações nos projetos durante a construção, retrabalhos, atrasos e orçamentos que distam da realidade.

A linearidade da estrutura do modelo tradicional foi observada por Clevenger (2014) em um estudo de caso a respeito da entrega integrada de projetos para a parte estrutural de edifícios de concreto armado. $\mathrm{O}$ autor observou que qualquer atraso em uma das etapas do processo acarreta atraso em todas as outras. Uma alternativa ao processo tradicional é o desenvolvimento tanto das etapas de projeto quanto de construção em ambientes colaborativos, criando uma maior integração entre os agentes envolvidos na produção da obra.

Em um ambiente colaborativo, como mostrado na Figura 12, todos os atores envolvidos nas fases de projeto e produção de determinada obra estão relacionados entre si, e o proprietário também faz parte desse processo. Dessa forma, o papel do projetista, por exemplo, não é finalizado com a conclusão do projeto, todos estão envolvidos até a entrega da obra. 


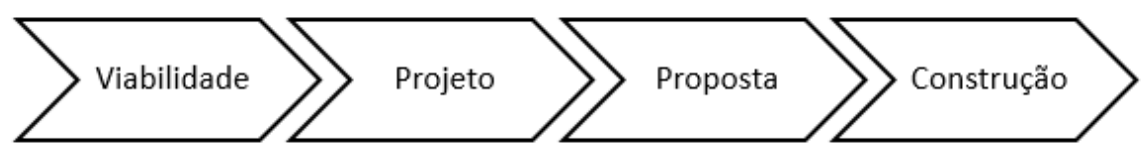

FIGURA 11 - Sistema tradicional de produção de obras.

FONTE: Autoria Própria.

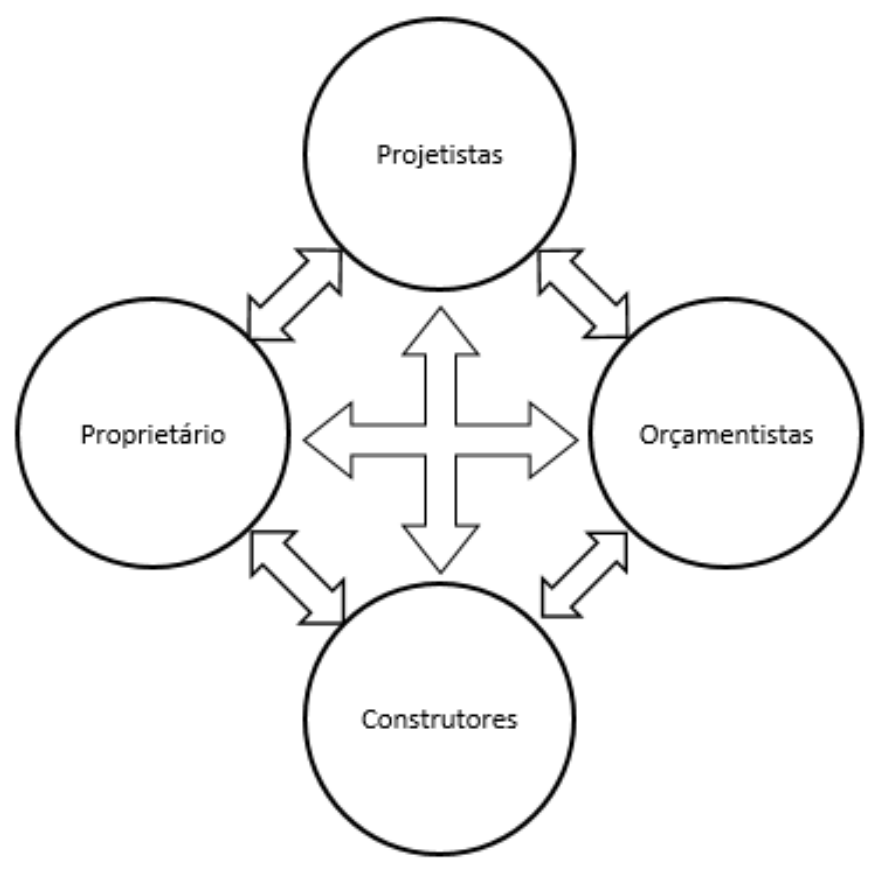

FIGURA 12 - Ambiente colaborativo na indústria da construção.

FONTE: Autoria Própria.

Segundo Sebastian (2010) "o trabalho de desenho e projeto colaborativo pode ser definido como um método de trabalho que visa integrar as informações de todas as equipes multidisciplinares do projeto, durante a fase de desenho e projeto".

É importante que além de criar um ambiente colaborativo, o gerente responsável pela coordenação dos projetos saiba o momento certo de revisar os projetos, pois em um ambiente ideal, os próprios colaboradores podem ter acesso aos outros projetos e assim identificar possíveis conflitos entre elementos como, por exemplo, tubulações de água fria que passem no meio dos vãos de vigas. Uma liderança eficiente é apontada por Dossick e Neff (2010) como uma das chaves para o sucesso de projetos desenvolvidos em plataforma BIM.

Em um estudo de caso realizado por Linderoth (2010), o gerente de projetos de uma construtora afirmou que após a implementação do BIM na empresa, o processo de projeto se tornou mais transparente e os consultores não podem mais esconder seus projetos.

De acordo com Cao et al. (2015) apesar do grande potencial, o avanço do BIM na indústria da construção ainda está em um estado inicial, e a atual taxa de difusão das tecnologias entre os profissionais dessa indústria em todo o mundo ainda é bem menor do que o esperado. Campestrini (2015) corrobora esta visão, afirmando que atualmente o BIM está sendo usado apenas como uma ferramenta no processo de desenvolvimento de projeto tradicional, e não exatamente como um novo processo de desenvolvimento de projetos por inteiro.

Um dos motivos que leva essa baixa taxa é a forma como o BIM é utilizado nas empresas, pois em conceito, a modelagem deve ser desenvolvida em ambiente colaborativo, onde os engenheiros, arquitetos e gestores trabalham de maneira integrada. No entanto, o que se observa em diversos casos é que os responsáveis pelos 
diversos projetos de uma obra não compartilham seus modelos entre si.

De acordo com Dossick e Neff (2010) enquanto o BIM mantém os participantes do projeto mais próximos tecnologicamente, eles ainda permanecem separados de uma maneira organizacional, frequentemente faltando acesso à informações e decisões. Tal fato advém da situação em que as partes integrantes do projeto adotam o BIM como ferramenta para desenvolver seus projetos em ambiente $3 \mathrm{D}$, entretanto, na hora de compartilhar o resultado com as outras frentes de trabalho, apenas as pranchas são repassadas.

Lu et al. (2014) afirma que "o cliente geralmente assina contratos com arquitetos, engenheiros e empreiteiros, partes que nem sempre trabalham eficientemente juntos e podem, de fato, ter interesses que competem entre si".

Em um estudo realizado por Won et al. (2016) a respeito da redução de desperdícios em projetos feitos em BIM, observouse no estudo de caso realizado a falta de integração entre os participantes do projeto, uma vez que a firma de arquitetura não forneceu os seus modelos de projeto para o empreiteiro, o qual teve de refazer a modelagem para a etapa de construção.

Cao et al. (2015) realizou um estudo das práticas e eficácia do uso do BIM em projetos de construção na China, chegando à conclusão de que o uso do BIM nas empresas se estendeu das fases de projeto para a utilização nas etapas da construção, porém o seu potencial ainda não é totalmente explorado.

\subsection{IMPREMENTAÇÃO DA PLATAFORMA BIM EM UMA EMPRESA}

Quando se analisa a etapa de implementação sob o ponto de vista das empresas responsáveis pelo projeto, é necessário que seja elaborado um plano de implantação prevendo a adoção em fases. Segundo Migilinskas (2013) um dos obstáculos para a implantação do BIM em empresas é a falta de informação sobre padrões e regras de implementação. De acordo com a AGC (2007) a melhor forma de começar a utilizar o BIM é ter um plano certo e segui-lo da maneira mais simples, definindo os objetivos que devem ser cumpridos pela empresa.

Para liderar a implementação devem ser escolhidas pessoas chave dentro da empresa, interessadas em BIM e que sejam proativas para as eventuais tomadas de decisões que se façam necessárias no processo.

Inicialmente deve ser ministrado um treinamento básico para um grupo reduzido de funcionários que estarão aptos a realizar a modelagem e detalhamento de edifícios na plataforma BIM. Após o treinamento para o grupo inicial, podem ser ministrados treinamentos para o restante da empresa. Dessa forma, a transição se dará de maneira gradual, com novos projetos sendo modelados já em BIM, e os modelos 2D que já estão em desenvolvimento sendo convertidos para o 3D. O plano de implantação deve prever ainda os softwares a serem adotados, configuração dos sistemas da empresa, preparo de modelos e bibliotecas, servidores e procedimentos de revisão dos projetos tanto pela gerência quanto pelos colaboradores do projeto.

É comum que as empresas escolham implantar o BIM visando a melhoria da qualidade dos desenhos e compatibilização dos projetos, mas que posteriormente, também apreciem as vantagens no estágio de produção. Tal fato deve ser considerado no plano de implantação, que deve prever as formas de utilização do BIM.

Essa nova forma de gestão de projetos, quando adotada, pode implicar na revisão do modelo de negócios da empresa, devido a alteração em campos como: parceiros chave, recursos chave, estruturas de custos, formas de relacionamento com o cliente, entre outros. O Quadro 3 traz os dados da alteração de horas de trabalho de acordo com cada perfil de trabalho após a implementação do BIM. Nota-se a redução das horas de trabalho em atividades ligadas diretamente ao projeto, enquanto que os gerentes e arquiteto sênior podem ter um acréscimo em suas horas devido às atividades de compatibilização e revisão. Para os arquitetos, pode ser observado que os que possuem 
hierarquia inferior têm suas horas de trabalho reduzidas, pois antes da implementação do BIM suas atividades eram mais ligadas à atividades de desenho e detalhamento.

Eastman et al. (2014) afirma que considerando o inevitável custo adicional da implementação de novos sistemas, o retreinamento de pessoal e o desenvolvimento de novos procedimentos as empresas podem assumir que os benefícios não valem a pena, porém os significativos custos iniciais associados ao resultado da transição trazem benefícios de produtividade no nível de documentação do edifício.

Lu et al. (2014) fez um estudo da análise custo-benefício da implementação do BIM em projetos de construção em Hong Kong, chegando à conclusão de que na fase de projeto o uso do BIM aumentou os custos em $45,93 \%$ (na cotação atual do dólar equivale a $13 \mathrm{US} \$ / \mathrm{m}^{2}$ ), porém ao analisar os custos totais do empreendimento, incluindo a etapa de construção, foi observada uma redução de $6,92 \%$ (na cotação atual do dólar equivale a 63,25 US\$ $/ \mathrm{m}^{2}$ ) dos custos quando comparado à um projeto semelhante que utilizou do modelo tradicional.

Durante a realização do projeto $\mathrm{e}$ execução de uma obra, é comum que várias empresas trabalhem no mesmo projeto, tendo este panorama em vista, Linderoth (2010) afirma que a escolha do uso do BIM deve partir do proprietário, uma vez que ele é o maior beneficiário e tem o poder de exigir o seu uso. Entretanto, em estudo realizado por Lu (2014), foi observado que o uso do BIM representa um aumento de $27,05 \%$ nos custos de implementação do BIM na etapa de projeto sobre os proprietários.

Existem dois tipos de proprietário, os que operam, ou que constroem para posteriormente ocupar a edificação, para usos comerciais, residenciais e outros. E os incorporadores que são os que constroem para depois vender. Os incorporadores podem evitar a adoção de ferramentas que demandem um custo de implantação, uma vez que eles visam altas taxas de retorno sobre investimentos. Os proprietários que usufruem da edificação são mais propícios a arcarem com despesas que aumentem a qualidade da construção.

No caso particular onde o proprietário ou cliente se trata do Estado e se deseje a utilização do BIM nos projetos que concorrem nos processos licitatórios, podem ser propostas leis específicas exigindo a entrega dos projetos nesta plataforma. De acordo com Cao et al. (2015) e Lu et al. (2014) algumas agências governamentais de países como Singapura, Coréia do Sul, Reino Unido, Dinamarca, Finlândia, Hong Kong e Estados Unidos estabeleceram planos para o uso obrigatório do BIM em projetos públicos.

QUADRO 3: Demanda por perfis de projeto em um empreendimento típico.

\begin{tabular}{|c|c|c|c|}
\hline \multirow{2}{*}{ Qualificação profissional } & \multicolumn{3}{|c|}{ Horas de projeto } \\
\cline { 2 - 4 } & Antes do BIM & Depois do BIM & Alteração \\
\hline Diretor & 32 & 32 & $33 \%$ \\
\hline Administrador do empreendimento & 128 & 192 & $40 \%$ \\
\hline Arquiteto sênior & 192 & 320 & $-67 \%$ \\
\hline Arquiteto júnior 1 & 320 & 192 & $-233 \%$ \\
\hline Arquiteto júnior 2 & 320 & 96 & $-19 \%$ \\
\hline Total & 992 & 832 & \\
\hline
\end{tabular}


Segundo Eastman et al. (2014) para considerar uma aplicação BIM os proprietários não devem simplesmente considerar seu impacto nos custos iniciais, mas também nos custos recorrentes, os quais podem superar os iniciais em uma proporção de até 2:1. A implementação do BIM em empresas foi estudada por Shou et al. (2015) e Migilinskas (2013).

Quando se trata de construtores que desejam adotar o BIM em seus projetos, é importante considerar como se dá a relação com a equipe de projeto. Em um ambiente colaborativo de entrega integrada de projetos, o construtor terá acesso fácil aos modelos, podendo extrair as informações de seu interesse e realizar o planejamento da obra. Entretanto, quando a obra é planejada no sistema tradicional, com as fases definidas de planejamento - proposta construção, conforme já mostrado na Figura 11, o construtor só terá acesso às informações após a etapa de concorrência. Caso a etapa de projeto tenha sido modelada em ambiente $2 \mathrm{D}$, a equipe de planejamento da obra deverá realizar a atualização do modelo para a plataforma BIM.

\subsection{MULTIDIMENSIONALIDADE}

A quantidade de informações que podem ser incluídas em um projeto é vasta. Além da geometria propriamente dita existem informações sobre o cronograma de atividades, relações de custo, gerenciamento de facilidades e manutenção, entre outros. O uso do BIM torna possível que todos os dados relativos ao projeto sejam combinados em um único bando de dados, originando a modelagem nD (SAKAMORI, 2015). O conceito de multidimensionalidade aplicado ao BIM foi inicialmente proposto por Aouad et al. (2003) como citado por Sakamori (2015).

A montagem desse banco de dados permite $o$ acesso a informações concisas de qualquer etapa do empreendimento (LEE, WU e AOUAD, 2007). Detalhes para construção como plantas, vistas e elevações, além de quantitativos podem ser extraídos de maneira automática. Tais informações, por sua vez, dependem da quantidade de detalhes com o qual o modelo foi construído.

\subsubsection{BIM 3D}

O modelo tridimensional do BIM é a base de toda a modelagem das informações. Nele são contidas as referências espaciais de todos os elementos presentes no projeto (pilares, vigas, paredes, portas, janelas, tubulações, equipamentos especiais etc.) (CAMPESTRINI et al., 2015). Entretanto, O BIM 3D vai além das informações geométricas, devendo ser previstos no lançamento destes elementos as especificações de materiais e acabamentos para que sejam gerados quantitativos consistentes com a realidade (LEE, WU e AOUAD, 2007).

Em fases iniciais da modelagem, podem ser utilizados elementos com uma menor quantidade de detalhes, sendo estes melhor detalhados com o decorrer do processo de projeto. Objetos compostos por várias camadas (por exemplo, paredes) podem ser atualizados com facilidade após a especificação de revestimentos. A Figura 13 exemplifica alguns dos modelos de paredes que podem ser configurados no ambiente do Revit $^{\circledR}$, partindo de um elemento sem camadas (à esquerda) até um muro com uma pingadeira associada (à direita).

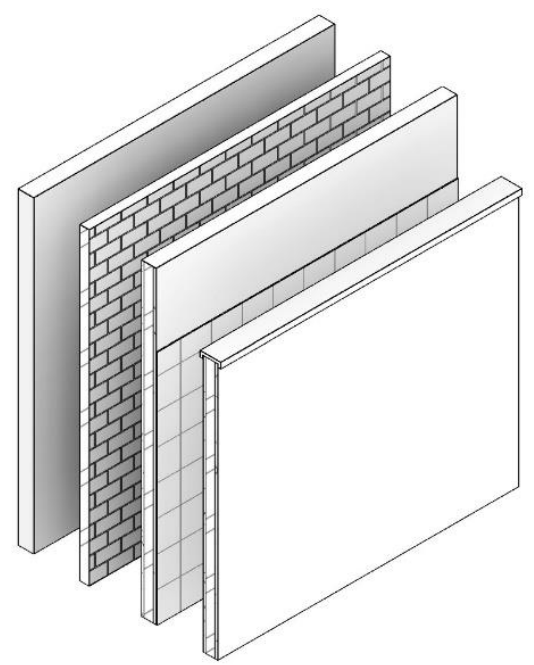

FIGURA 13 - Tipos de paredes configuráveis no Revit ${ }^{\circledR}$, FONTE: Autoria Própria.

Bryde, Broquetas e Volm (2013) ponderam que no BIM 3D as informações de todas 
as disciplinas e documentação do projeto devem estar em formato eletrônico. Desta forma é possível seja feita a comparação entre os arquivos das disciplinas para realizar uma análise global de conflitos. Tal verificação permite que o projeto seja otimizado no momento da concepção, evitando a necessidade de retrabalho com compatibilização ou até mesmo adaptações no canteiro (Ll et al., 2014).

\subsubsection{BIM 4D}

Com o banco de dados contendo todos os elementos físicos que compõem o empreendimento é possível adicionar mais uma dimensão ao projeto. Usualmente a quarta dimensão, ou BIM 4D, faz referência à adição do cronograma da obra ao arquivo (CAMPESTRINI et al., 2015).

O modelo 4D mantem um vínculo com os modelos 3D. Desta forma é importante notar que não é impossível realizar uma modelagem verdadeiramente tetradimensional sem um modelo tridimensional em mãos (EASTMAN et al., 2014).

Entretanto, tal aspecto permite que sejam analisados os impactos das alterações feitas na geometria do empreendimento diretamente no tempo das tarefas a serem executadas. Levando à implementação de cronogramas mais completos e melhor fundamentados (EASTMAN et al., 2014).

Eastman et al. (2014) comenta que as simulações permitidas pelo modelo 4D "funcionam principalmente como ferramentas de comunicação para revelar potenciais gargalos e como um método para melhorar a colaboração". O autor cita como benefícios da modelagem 4D:

- Comunicação: Existe uma melhor idealização dos aspectos temporais e espaciais, permitindo uma comunicação visual do processo construtivo.

- Logística do canteiro: É possível administrar as áreas de estocagem, bem como os acessos aos canteiros e locação de equipamentos.

- Coordenação de disciplinas: É possível organizar de maneira mais efetiva 0 trabalho de equipes multidisciplinares de modo a otimizar o tempo das tarefas a serem executadas.

- Comparação de cronogramas: Diferentes programações podem facilmente ser comparadas.

- Acompanhamento do progresso da construção: O progresso da construção pode ser acompanhado dia-a-dia com o progresso do modelo tridimensional do projeto.

\subsubsection{BIM 5D}

$\mathrm{Na}$ modelagem BIM 5D são incluídas as informações relativas aos custos da obra no modelo. Pela inclusão de dados relativos aos serviços (custos materiais, mão de obra e equipamentos, despesas diretas e indiretas e bônus etc.) é possível analisar diretamente nos custos o impacto de modificações no projeto (CAMPESTRINI et al., 2015). Desta forma podem ser tomadas decisões mais eficazes (SAKAMORI, 2015), construindo edificações de forma mais viável e confiável (EASTMAN et al., 2014).

É importante ressaltar que, assim como no BIM 4D, existe uma dependência do modelo tetradimensional para que seja construído o modelo 5D (STAUB-FRENC, 2007). Tal subordinação é justificável, visto que o tempo tem impacto direto nos custos do empreendimento (SAKAMORI, 2015).

\subsubsection{BIM nD}

Essencialmente, podem ser incluídas infinitas dimensões numa modelagem BIM. Devido à extensa quantidade de disciplinas envolvidas num projeto de engenharia, a modelagem $\mathrm{nD}$ ou multidimensional permite que sejam analisados o impacto de diferentes aspectos na construção, de maneira holística e efetiva (FISHER, 2007).

Com o avanço da tecnologia é possível observar um horizonte onde o desenvolvimento da modelagem possibilitará uma completa simulação virtual das edificações (BRYDE, BROQUETAS e VOLM, 2013; FROESE, 2010). Analisando todos os mínimos aspectos antes que o empreendimento 
seja levado ao mundo real, permite-se resolver todos os prováveis problemas que serão gerados tanto na obra quanto na vida da edificação.

Dentre os aspectos que podem ser adicionados na modelagem Lee et al. (2005) cita:

- Análise do ciclo de vida;

- Maximização da sustentabilidade;

- Investigações sobre exigências energéticas;

- Análises de acessibilidade;

- Gestão de facilidades;

- Análises acústicas.

\section{CONCLUSÕES}

A análise dos trabalhos torna possível afirmar que o estudo do Building Information Modelling avança a passos largos. A busca, da indústria, por soluções que ofereçam projetos de melhor qualidade, aliada à integração da tecnologia da informação nos canteiros de obra é o horizonte perfeito para a expansão da tecnologia.

A utilização de modelos tridimensionais plenos e efetivos reduz a possibilidade de erros já em etapas preliminares de concepção. Sendo assim, a vertente de pesquisa "Equipes Colaborativas" corrobora uma busca pela desfragmentação do processo de projeto. Pode ser antecipada uma fronteira onde todas as equipes envolvidas trabalharão consonantemente juntas.

A avaliação das capacidades de integração entre as disciplinas, principalmente focada na compatibilização de projetos e análise de interferência é uma lacuna importante que precisa ser mais discutida e estudada. Entretanto, para uma real verificação de todas as vantagens e possibilidades do BIM faz-se necessária sua implantação integral. Como a transição entre o projeto $2 \mathrm{D}$ e $3 \mathrm{D}$ se torna penosa, até a adoção da nova plataforma por todos os envolvidos, existe ainda uma desconfiança quanto à implantação da mesma.

Finalmente, cabe-se destacar a importância da aplicação de Mapeamentos Sistemáticos tanto para o direcionamento das pesquisas já desenvolvidas, quanto na verificação da existência de hiatos nos assuntos pesquisados.

\section{REFERÊNCIAS BIBLIOGRÁFICAS}

ASSOCIATED GENERAL CONTRACTORS OF AMERICA (AGC). The contractors guide to BIM. 1. ed. [S.I.]: AGC, 2007.

BRYDE, D.; BROQUETAS, M.; VOLM, J. M. The project benefits of Building Information Modelling (BIM). International Journal of Project Management, v. 31, p. 971-980, Outubro 2013.

BUILDING SMART. What is a BIM? buildingSMART, 2010. Disponivel em: <http://buildingsmart.org/>. Acesso em: 29 Dezembro 2016.

CAMPESTRINI, T. F.; GARRIDO, M. C.; MENDES JÚNIOR, R.; SCHEER, S.; FREITAS, M. C. D. Entendendo BIM: Uma visão do projeto de construção sob o foco da informação. Curitiba: Universidade Federal do Paraná, 2015. 120 p.

CAO, D.; WANG, G.; LI, H.; SKITMORE, M.; HUANG, T.; ZHANG, W. Practices and effectiveness of building information modelling in construction projects in China. Automation in Construction, n. 49, p. 113-122, 2015.

CHIEN, K. F.; WU, Z. H.; HUANG, S. C. Identifying and assessing critical risk factors for BIM projects: Empirical study. Automation Construction, p. 1-15, Abril 2014.

CLEVENGER, C. M.; KHAN, R. Impact of BIM-Enabled Design-to-Fabrication on Building Delivery. Practice Periodical on Structural Design and Construction, v. 19, n. 1, p. 122 - 128, Fevereiro 2014.

COSTA, C. H. A.; STAUT, S. L. S.; ILHA, M. S. O. Projeto de sistemas prediais hidráulicos sanitários com BIM: mapeamento de literatura. XV Encontro Nacional de Tecnologia do Ambiente Construído, Maceió, p. 2760 2769, Novembro 2014.

DOSSICK, C. S.; NEFF, G. Organizational Divisions in BIMEnabled Commercial Construction. Journal of Construction Engineering and Management, v. 136, n. 4, p. 459 - 467, Abril 2010.

EASTMAN, C.; TEICHOLZ, P.; SACKS, R.; LISTON, K. Manual de BIM: um guia para modelagem da informação da construção para arquitetos, engenheiros gerentes, construtores e incorporadores. Tradução de Cervantes Gonçalves Ayres Filho; Kléos Magalhães Lenz César Junior, et al. Porto Alegre: Bookman, 2014.

EPG - E.P. GUIDI, INC. Springfield Literacy Center. Disponível em:

http://epguidi.com/portfolio/education/springfieldliteracy-center. Acessado em 20 de março de 2017.

FISHER, M. Prefácio. In: AOUAD, G.; LEE, A.; WU, S. Constructing the Future: nD Modelling. Oxônia: Taylor \& Francis, 2007. p. XIX-XX. 
GENERAL SERVICES ADMINISTRATION. GSA BIM Guide Series. Washington, p. 210-215. 2007.

GU, N.; LONDON, K. Understanding and facilitating BIM adoption in the AEC industry. Automation in Construction, Newcastle, n. 19, p. 988-999, Janeiro 2010.

HILL, M. The business value of BIM: getting to the bottom line. Smart Market Report, p. 1-52, 2009. Disponivel em: <http://www.bim.construction.com/research/2009>.

HU, Z.; ZHANG, X.; WANG, H.; KASSEM, M. Improving interoperability between architectural and structural design models: An industry foundation classes-based approach with web-based tools. Automation in Construction, v. 66, p. 29 - 42, 2016.

KRAATZ, J. A.; SANCHEZ, A. X.; HAMPSON, K. D. Digital Modeling, Integrated Project Delivery and Industry Transformation: An Australian Case Study. buildings, v. 4, p. 453-466, Setembro 2014.

LEE, A.; WU, S.; MARSHALL-PONTING, A.; AOUAD, G.; COOPER, R.; TAH, J. H. M.; ABBOTT, C.; BARRETT, P. S. nD Modelling Road map: A Vision for nD-Enabled Construction. Salford: University of Salford, 2005.

LI, J.; HOU, L.; WANG, X.; WANG, J.; GUO, J.; ZHANG, S.; JIAO, Y. A Project-based Quantification of BIM Benefits. International Journal of Advanced Robotic Systems, v. 11, p. 1-13, agosto 2014.

LINDEROTH, H. C. J. Understanding adoption and use of BIM as the creation of actor networks. Automation in Construction, v. 19, p. 66-72, 2010.

LU, W.; FUNG, A.; PENG, Y.; LIANG, C.; ROWLINSON, S. Cost-benefit of Building Information Modelling implementation in building projects through demysfitication of time-effort distribution curves. Building and Environment, v. 82, p. 317-327, 2014.

MENA, G. A.; CRAWFORD, J.; CHEVEZ, A.; FROESE, T. Building information modelling demystified: Does it make business sense to adopt BIM? International Journal of Managing Projects in Business, v. 2, n. 3, p. 419-434, 2009.

MIETTINEN, R.; PAAVOLA, S. Beyond the BIM utopia: Approaches to the development and implementation of building information modeling. Automation in Construction, v. 43, p. 84-91, Julho 2014.

MIGILINSKAS, D.; POPOV, V.; JUOCEVICIUS, V.; USTINOVICHIUS, L. The Benefits, Obstacles and Problems of Practical Bim Implementation. Procedia Engineering, v. 57, p. 767 - 774, 2013.

OH, M.; JAEWOOK, L.; HONG, S. W.; JEONG, Y. Integrated system for BIM-based collaborative design.
Automation in Construction, v. 58, p. 196-206, Julho 2015.

PAS 1192-2. Specification for information management for the capital/delivery phase of construction projects using building information modelling. [S.I.]: The British Standards Institution 2013, v. I, 2013.

PAULA, H. M. D.; ILHA, M. S. D. O. Uso da Moringa oleifera no tratamento de águas residuárias de usinas de concreto: mapeamento sistemático. REEC - Revista Eletrônica de Engenharia Civil, v. 11, n. 1, p. 50 - 60, 2016.

SAKAMORI, M. M. MODELAGEM 5D (BIM) - PROCESSO DE ORÇAMENTAÇÃO COM ESTUDO SOBRE CONTROLE DE CUSTOS E VALOR AGREGADO PARA EMPREENDIMENTOS DE CONSTRUÇÃO CIVIL. 2015. 178f. Dissertação (Mestrado em Construção Civil) Universidade Federal do Paraná. Curitiba. 2015.

SEBASTIAN, R. Integrated Design and Engineering using Building Information Modelling: A Pilot Project of SmallScale Housing Development in The Netherlands. Architectural, Engineering and Design Management, v. 6, p. 103-110, 2010.

SHOU, W.; WANG, J.; WANG, X.; CHONG, H. Y. A Comparative Review of Building Information Modelling Implementation in Building and Infrastructure Industries. Archives of Computational Methods in Engineering, v. 22, p. 291 - 308, 2015.

SMITH, P. BIM \& the 5D Project Cost Manager. Procedia - Social and Behavioral Sciences, Sydney, v. 119, p. 475484, 2014

STAUB-FRENC, S. 3D and 4D modeling for design and construction coordination: issues and lessons learned. ITcon, v. 12, p. 381-407, Julho 2007.

WON, J.; CHENG, J. C. P.; LEE, G. Quantification of construction waste prevented by BIM-based design validation: Case studies in South Korea. Waste Management, v. 49, p. 170-180, 2016.

WOO, J.; WILSMANN, J.; KANG, D. Use of as-built building information modeling. Construction Research Congress 1. Milwaukee: [s.n.]. 2010. p. 538-547.

ZUPPA, D.; ISSA, R. R. A.; SUERMANN, P. C. BIM's impact on the sucess measures of construction projects. Computing in Civil Engineering. Gainesville: [s.n.]. 2009. p. 503-512. 